ing theories of greenhouse warming with Earth's temperature record over the past century and for estimating the response to time-evolving concentrations of greenhouse gases next century. I believe the results I have discussed make a case for diagnosis and intercomparison of oceanic general circulation models, analogous to comparison of atmospheric models ${ }^{4}$, with emphasis on rate of response to external perturbations.

CuRT CoveY

Atmospheric and Geophysical Sciences Division,

Lawrence Livermore National Laboratory,

Livermore, California 94551, USA

1. Hansen, J. et al. Science 229, 857-859 (1985).

2. Wigley, T. M. L. \& Schlesinger, M. E. Nature 315 , $649-652$ (1985).

3. Harvey, L. D. D. J. geophys. Res. 91, 2709-2717 (1986)

4. Cess, R. D. et al. Science 245, 513-516 (1989).

5. Hansen, J. et al. in Climate Processes and Climate Sensitivity (ed Hansen, J. \& Takahashi, T.) 130-162 (American Geophysical Union, Washington, 1984).

6. Schlesinger, M. E. Climate Dynamics 1, 35-51 (1986).

7. Washington, W. M. \& Meehl, G. A. Climate Dynamics 4, 1-38 (1989).

8. Manabe, S., Bryan, K. \& Spelman, M. J. J. phys. Oceanogr. 20, 722-749 (1990).

9. Sausen, R., Lunkeit, F. \& Oberhuber, J. M. in Research Activities in Atmospheric and Oceanic Modeling (ed. Boer, G. J.) 9.4-9.5 (WMO, Geneva, 1990).

\section{Rhythms of war}

SIR - Schreiber et al. proposed ${ }^{1}$ that seasonal rhythms influence the opening dates of wars, based on the observed significant correlation between daily photoperiod and the dates of commencement of acts of aggression ${ }^{2}$. They assigned this correlation to increased aggression induced by long photoperiods. Their published correlations were indeed quite remarkable for data from both the Northern and Southern Hemispheres and from the Equator.

However, as with all such comparisons and correlations, an understanding of underlying principles and of the nature of the dataset should be applied to the interpretation of the results. What this high correlation may in fact identify is a relationship between the season and military strategy over the past few thousand years. It seems logical that military strategists should make use of good conditions (including long photoperiod) to move men and equipment, and that they would plan campaigns accordingly. The failure to respond to climate conditions while planning and executing wars has been illustrated by more than one disastrous campaign.

Imperial Cancer Research Fund,

ROBERT BENNETT London WC2A 3PX, UK

1. Schreiber, G., Avissar, S. \& Tzahor, Z. Nature 349. 574-575 (1991)

2. Laffin, J. Brassey's Battles: 3500 Years of Conflict (Pergamon, London, 1986)

\section{Krill abundance}

SIR - Antarctic krill (Euphausia super$b a$ ) is the primary food source for many animals in the southern ocean and is also the basis of a large fishery. To manage this resource, krill abundance has been estimated directly with acoustics and indirectly with estimates of predator consumption rates. However, the abundance estimates using acoustics are often an order of magnitude less than those based on predator consumption rates ${ }^{1}$. The acoustic method converts echo energy to absolute biomass by assuming that the echo return is the sum of individual scatterers, and by assuming an empirical or modelled acoustic target strength (TS) for individual krill. Everson et al. ${ }^{2}$ and Greene et $a l .^{3}$ reported new TS measurements of experimentally constrained krill, but to date no corroborating field data have been published. We present new in situ TS measurements of krill obtained in March 1991 off Elephant Island, Antarctica.

Foote et al. ${ }^{1}$ ensonified live krill aggregations in a cage at $120 \mathrm{kHz}$. The mean single-animal target strength of krill (lengths 30-39 $\mathrm{mm}$ ) was inferred from the aggregation backscatter to range from -81 to $-74 \mathrm{~dB}$. Past acoustic surveys have typically used TS values
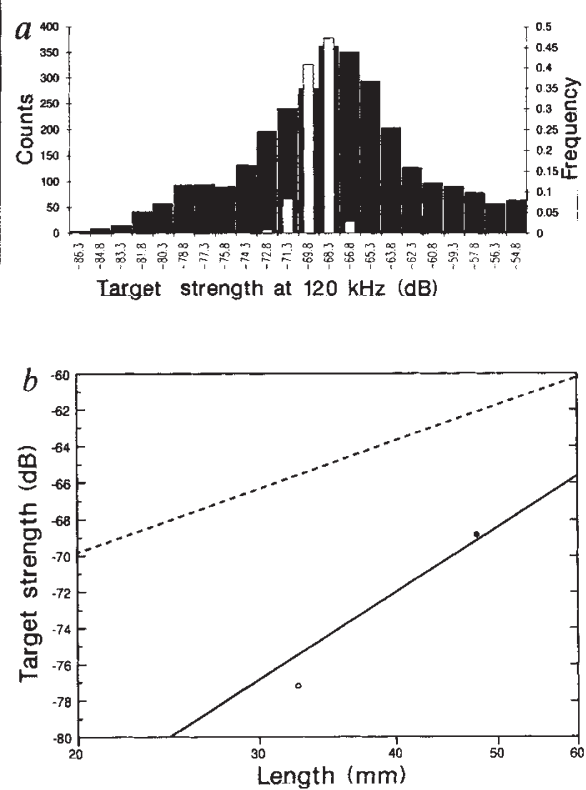

a, TS distribution for 2,957 individual krill detected with a Simrad EK500 echo sounder and a $120-\mathrm{kHz}$ split-beam transducer off Elephant Island, Antarctica in March 1991. Solid bars, in situ measurements; open bars, distribution predicted from the sampled distribution of animal lengths. $b$, TS by length relationship at $120 \mathrm{kHz}$. Solid line reproduced from ref. 3. Also plotted are the median length and TS from the Foote et al. experiment (open circle) ${ }^{1}$, the data reported here (solid circle), and the BIOMASS equation (dotted line). calculated using the equations from the BIOMASS $^{4}$ program, but these equations lead to gross underestimates of krill abundance 2 .

Until recently, a fluid sphere model was thought to characterize adequately the acoustic TS of krill. Wiebe et al. ${ }^{5}$ ensonified several species of live, but tethered, zooplankton at $420 \mathrm{KHz}$ and concluded that sound scatter from elongated animals is better described by a bent cylinder model ${ }^{6}$ and that $\mathrm{TS}$ is proportional to the volume of an animal rather than its cross-sectional area. Using these data, Greene et $a l^{3}$ predicted krill TS at several frequencies and over a range of animal lengths. The Foote $e t$ al. data agree with the TS prediction for a mean animal size of $33 \mathrm{~mm}$. Because the bent cylinder model predicts that TS is much more sensitive to animal length than would be expected with the fluid sphere model, additional measurements of krill TS, particularly at different lengths, could provide strong corroboration of refs 1 and 3 .

We present in-situ TS measurements of krill (mean length $=47.44 \mathrm{~mm}, \sigma=$ 2.92), around Elephant Island ( $a$ in the figure). Zooplankton sound scattering depends upon the morphology of the animal as well as its size, shape and orientation $^{5}$. The spread of the distribution is likely due to the size distribution and variable orientation of the ensonified krill. Some of the high TS observations may be from multiple krill erroneously identified as individual scatterers. Nonetheless, the distribution is centred on $-69 \mathrm{~dB}$, within $1 \mathrm{~dB}$ of the prediction by Greene et al. Furthermore, the slope between the Foote et al. data and the data presented here is in accordance with that predicted by the bent cylinder model.

The TS of $47.44-\mathrm{mm}$ krill estimated from the BIOMASS equations is -62.3 $\mathrm{dB}, 6.7 \mathrm{~dB}$ above the modal value of the measurements reported here. Thus, for a population composed of 47.44-mm individuals, abundance estimates using the mean TS reported here would be 4.7 times higher than that estimated with the BIOMASS value.

\section{Southwest Fisheries Science Center.} La Jolla, California 92038, USA

DAVID A. DEMER

Scripps Institution of Oceanography,

University of California at San Diego

La Jolla, California 92038, USA

\footnotetext{
1. Foote, K. G., Everson, I., Watkins, J. L. \& Bone, D. G Acoust. Soc. Am. 87, 16-24 (1990).

2. Everson, I., Watkins, J. L., Bone, D. G. \& Foote, K. G. Nature 345, 338-340 (1990).

3. Greene, C. H., Wiebe, P. H. \& McClatchie, S. Nature, 349, 110 (1991).

4. Post-Fibex Acoustic Workshop BIOMASS Report Ser. No. 40 (1986).

5. Wiebe, P. H., Greene, C. H., Stanton, T. K. \& Burczynski, J. J. Acoust. Soc. Am. 88, 2346-2360 (1990). 6. Stanton, T. K. J. Acoust. Soc. Am. 86, 1499 (1989).
} 